\title{
Impact Of Pragya Yoga Exercise On Lipid Profile Among Overweight Women RIDDHI SAHU
}

\begin{abstract}
Obesity is defined as abnormal or excessive fat accumulation that presents risks for many other disorders. It is affecting populations across the world in all age groups which may be caused due to unhealthy lifestyles or genetic predisposition. The present study was conducted to assess the impact of pragya-yoga exercise (a defined set of 16 yogic postures) on lipid profile among overweight women. 30 overweight women $(\mathrm{BMI}>25 \mathrm{~kg} / \mathrm{m})$ were selected from the polyclinic of Dev Sanskriti university Haridwar, with their ages ranging from 30 to 50 years (group average age \pm S.D., 38.37 \pm 5.52 years). All participants practiced Pragya Yoga exercise for 40 minutes on each day for eight weeks under supervision of a female yoga therapist. Data was analyzed using paired sample t-test. There were statistically significant reduction in total cholesterol level $(\mathrm{df}=28, \quad \mathrm{p}<0.01)$, total triglyceride level $(\mathrm{df}=28, \quad \mathrm{p}<0.01), \quad$ low density lipoprotein $(\mathrm{df}=29, \mathrm{p}<0.01)$ and significant elevation in high density lipoprotein $(\mathrm{df}=29, \mathrm{p}<0.01)$. The result suggests that Pragya-yoga practices are beneficial for the management of lipid profile among overweight women.
\end{abstract}

Key words: Pragya-yoga exercise, lipid profile, overweight women 


\section{Introduction:}

With the advent of this fast paced technological world in the twenty first century, humans have become more prone to lifestyle related disorders owing to lack of physical activities and faulty dietary habits like prepackaged foods loaded with carbohydrates and sugars. These have resulted in a significant increase in the number of patients suffering from obesity (Kushi , L.H.2006).

Obesity is defined as abnormal or excessive fat accumulation that presents a risk to health. It is a treatable disease that is a worldwide health concern (Shetty, B.2017). It is caused by genetic, environmental and dietary factors and can be difficult to control through dieting alone. A crude population measure of obesity is the body mass index (BMI), a person's weight (in kilograms) divided by the square of his or her height (in metres). A person with a BMI of 30 or more is generally considered obese. A person with a BMI equal to or more than 25 is considered overweight (Sayyed, A.2019).

The ill effects of obesity can be measured directly by the aid of biochemical markers i.e. lipid profile (ldl, hdl, vldl, chylomicrons). It provides the clear details of the amount of fat-linked bio- molecules that directly affect the state of obesity. The menace of obesity is affecting the population worldwide. The escalating pace of obesity if not controlled will surpass the population when it comes to malnutrition.

Yoga is an ancient Indian technique of healing the body and the mind that was developed by the ancient sages (Pullen, P.R.2008). It played a major role in improving and maintaining the lifestyle of people. Currently it has been revived to maintain the state of health and alleviate ill effects of diseases. There are various components of Yoga which include asanas (yogic postures), pranayams (breathing exercises) and dhyanas (meditation) (Sarvottam, K.2014).

According to Vedic philosophy, the root cause of all physical ailments lie in the emotional state of a human being. A disease is manifested in the form of disturbances in both physical and mental state. Hence to cure a disease, emphasis should be laid on both these aspects which would provide a holistic approach of treatment. Researchers have shown that inculcation of Yoga in life helps in decreasing hypertension, cardiac diseases and boosting our nervous system and psychological health (Vempati, R.P., Telles, S.2002). Pragya Yoga Vyayam which is a series of 16 aasanas practiced with breathing awareness along with chanting of mantras, developed by Pandit Sri Ram Sharma Acharya relaxes both mind and body.

Yoga as a therapeutic process, has been shown to be useful to individuals with cardiovascular disease and diabetes (Gadham , J.2015). Yoga is also beneficial in reducing body fat while decreasing the risk factors involved in atherosclerosis (Khre, 2002).

Studies have found that yoga and regular walking improved anthropometric variables and serum lipid profile in overweight and obese individuals. Raja-yoga meditation practitioners showed lower level of TC, TG, VLDL and FBS and higher level of HDL 
than non-practioners. An 8-week of yoga training module improved body composition and TC levels in obese adolescent boys, suggesting that yoga training may be effective in controlling some metabolic syndrome factors (Madape, A. 2015). 6 months practice showed significant reduction in total cholesterol, low-density lipoprotein (LDL) and triglycerides. Also there was a significant increase in the highdensity lipoprotein (HDL) (Mody, B.S. 2011).

In addition, in a study on Surya Namskar practiced by Indian participants (18-22 years) daily 30 minutes showed that daily practice of Surya namskar helped to improve cardio respiratory fitness, as well as promoted weight management (Nilakathan , S. 2016). If practiced for a reasonable time long enough to bring about a state of light perspiration, a reasonable amount of toxins can be eliminated from the body through the pores of the skin and thus maintain the sound body and mind status (Singh, S., 2001).

The effect of exercise therapy on fasting blood glucose, lipid profile, oxidative stress markers and anti oxidant status in patients with type 2 diabetes showed that 30 days hath-Yoga practices decreased LDL cholesterol and triglycerides level and improved HDL level (Prasad, K.V.V. 2006).

The asanas in pragya yoga could help in the balancing various functions of body and mind. Several reports have been made with regard to its effect on respiratory, hormonal, neural system, metabolic, muscle-strength and body-composition. The 3-month program was designed to change eating and activity patterns and to improve selfefficacy, quality of life, well-being, vitality, and self-awareness around food choices, stress management, and barriers to weight loss (Tells, S.,2014). The effect of exercise on blood lipid profiles was widely reported. Physical activity raised HDL levels and decreased the concentration of very lowdensity lipoprotein cholesterol and triglycerides. Physical activity and HDL appeared to be linked via HDL's role in triglyceride metabolism. The practice of yoga was reported to reduce body fat, the waist circumference and increase muscle strength in overweight and obese persons with Obesity (Dhananjai,S., 2013). Studies also shown that overweight and obese participants having experience in yoga significance increase in their quality of life in Yoga treatment group.

The present study was conducted to assess the impact of pragya-yoga exercise (a group of 16 yogic postures) on lipid profile among overweight women. Following were objectives of the study:

- To study the effect of pragya yoga exercise on total cholesterol level.

- To study the effect of pragya yoga exercise on total triglyceride level.

- To study the effect of pragya yoga exercise on HDL level.

- To study the effect of pragya yoga exercise on LDL level.

\section{Research methodology}

\section{Participants}

30 overweight women $\left(\mathrm{BMI} \geq 25 \mathrm{~kg} / \mathrm{m}^{2}\right)$ were selected from the polyclinic at Dev Sanskriti University, Haridwar with their ages ranging from 30 to 50 years. All participants practiced pragya yoga exercise 
for 40 minutes on each day for eight weeks under the supervision of a qualified female yoga therapist.

Inclusive criteria of the study

The inclusion criteria were, BMI $>25 \mathrm{~kg} / \mathrm{m}$, age range between 30 to 50 years. The participation of patients qualified in the study was voluntary without any remuneration.

Exclusive criteria of the study

The exclusive criteria were, doing any type of yogic exercises, taking antioxidant drugs, with any kind of addiction (smoking, tobacco chewing and alcohol intake), hypertension, cardio-vascular disorders or any other systemic disease were excluded.

Collection of blood sample \& Measurement of lipid Profile

Blood collection was done by venous method (middle cubital fossa). Collected blood serum was separated after 30 minute intervals. Lipid profile included total cholesterol test done by CHOD (cholesterol oxidaze method), Triglyceride (Tg) done by enzymatic methods), the HDL Cholesterol by phosphor tungstic method and LDL by formulation. All these tests were done under end point reaction slop by using semi autoanalyzer (RA 50 ERBA). The pretest results were obtained initially and the yogic intervention was given from the following day for eight weeks.

\section{Intervention}

Pragya Yoga exercise was practiced for 40 minutes per day for a period of eight weeks by the participants under the guidance of a qualified female yoga therapist. The timing of Pragya yoga classes were between 6:00 am to 7:00 am daily, except on Sundays. Pragya yoga has 16 steps comprising yogic postures and each step is associated with one of nine words of Gayatri mantra along with breath awareness. The intervention details are given in table 1 .

Table 1.Intervention of Pragya Yoga exercise

\begin{tabular}{ll}
\hline Yogic postures & Mantras \\
\hline Tadasana & Om bhooh \\
\hline Padahastasna & Om bhuvah \\
\hline Vajrasana & Om swah \\
\hline Ustrasna & Tat \\
\hline Yoga mudrasana & Savitur \\
\hline Ardhatadasna & Varenyam \\
\hline Shashankasna & Bhargo \\
\hline Bhujangasana & Devasya \\
\hline Tiryak bhujagasana(left) & Dhimahi \\
\hline Tirayak bhujangasana(right) & Dhiyo \\
\hline Shashankasana & Yonah \\
\hline Ardhatadasana & Prachodayat \\
\hline Utakatasna & Bhooh \\
\hline Padhastasna & Bhuvah \\
\hline Tadasana & Swah \\
\hline Tadasna and release & Chanting of Om \\
\hline
\end{tabular}




\section{Results}

Study data was analyzed using paired sample t-test. There were statistically significant reduction in total cholesterol level ( $\mathrm{df}=28, \mathrm{p}<0.01)$, total triglyceride level $(\mathrm{df}=28, \mathrm{p}<0.01)$, low density lipoprotein $(\mathrm{df}=29, \mathrm{p}<0.01)$ and significant elevation in high density lipoprotein $(\mathrm{df}=29, \mathrm{p}<0.01)$.

(Table 2-5).

Table 2. Comparison of Total cholesterol before and after practice of pragya yoga vyayam

\begin{tabular}{lllllll}
\hline & Mean & SD & df & $R$ & t-value & significance \\
\hline Pre & 192.79 & 40.95 & 28 & 0.986 & 6.31 & 0.01 \\
\hline Post & 182.62 & 34.85 & & & & \\
\hline
\end{tabular}

Table 3. Comparison of Total triglyceride before and after of pragya yoga vyayam

\begin{tabular}{ccccccc}
\hline & Mean & SD & Df & R & t-value & significance \\
\hline Pre & 173.96 & 62 & 28 & 0.98 & 8.28 & 0.01 \\
\hline Post & 152.62 & 54.07 & & & & \\
\hline
\end{tabular}

Table 4. Comparison of HDL before and after of pragya yoga vyayam

\begin{tabular}{ccccccc}
\hline & Mean & SD & Df & $r$ & t-value & significance \\
\hline Pre & 39.83 & 6.31 & 29 & 0.74 & 7.63 & 0.01 \\
\hline Post & 45.66 & 6.75 & & & & \\
\hline
\end{tabular}

Table 5. Comparison of LDL before and after of pragya yoga vyayam

\begin{tabular}{|c|c|c|c|c|c|c|}
\hline & Mean & SD & $\mathrm{Df}$ & $r$ & t-value & significance \\
\hline Pre & 91.3 & 9.55 & \multirow{2}{*}{29} & \multirow{2}{*}{0.83} & \multirow{2}{*}{3.13} & \multirow{2}{*}{0.01} \\
\hline Post & 86.26 & 9.28 & & & & \\
\hline
\end{tabular}




\section{Discussion}

Data were analyzed using paired sample ttest. There were statistically significant reduction in total cholesterol level $(\mathrm{df}=28$, $\mathrm{p}<0.01)$, total triglyceride level $(\mathrm{df}=28$, $\mathrm{p}<0.01)$, low density lipoprotein $(\mathrm{df}=29, \mathrm{p}<0.01)$ and significant elevation in high density lipoprotein $(\mathrm{df}=29, \mathrm{p}<0.01)$. therefore this signifies the success of pragya yoga on the lipid profile in over weight woman.

Research showed that the practice of pragya yoga vyayam could help maintain normal level of lipid profile. Coronary artery disease is a major cause of death in the modern age. It results from the deposits of cholesterol and fat, which leads to the blockage of arteries, which in turn obstructs supply of oxygen and blood to the heart muscles. The deficiency of blood and oxygen leads to angina and heart attacks. Diet (rich cholesterol diet), stress, high blood pressure, obesity, lack of physical activity, smoking etc. result in an exorbitant increase in the number of heart Disease. The conventional treatment of these includes medical management with the help of drugs. Therefore significant research should be done in this field to enable us to fight against these life threatening diseases.

\section{Conclusion}

Yoga is fundamentally different from conventional medical practice in its approach to healthcare. This research study showed that pragya yoga vyayam has a moderating effect on cholesterol level. This moderating effect could be used as supplementary treatment to cholesterol disorders. Though the study did not included randomized controlled group, rather it is a single arm study, yet it indicated the utility of Yogic practices especially Pragya Yoga in reducing cholesterol level. This study was performed only in women participants; further studies can be performed on a large heterogeneous sample size.

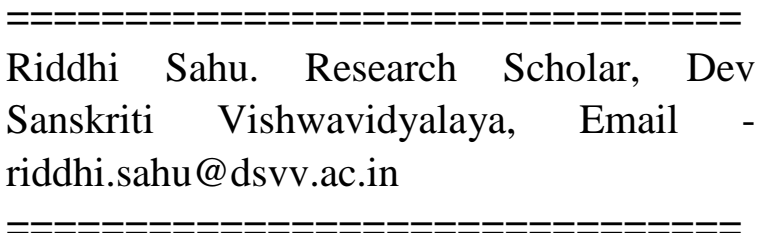




\section{References}

Kushi , L.H., Byers. T., Doyle C, et al. American Cancer Society guidelines on nutrition and physical activity for cancer prevention: reducing the risk of cancer with healthy food choices and physical activity.CA Cancer J Clin. 2006;56(5):254-81.

https://doi.org/10.3322/canjclin.56.5.254

Shetty, B., Geetha B Shetty, G.B., Manjunath N K, Shantaram, M.2017. Effect of Integrated Yoga Practices on Anthropometric Measures, Serum Lipid Profile and Oxidative Stress Status in Obese Adults. Indian Journal of Applied Research 7(1),942-944.

Sayyed, A., Patil, J., Chavan, V., Patil, S., Charugulla,S. Sontakke,A. and Kantak,N.2019. Study of Lipid Profile and Pulmonary Functions in Subjects Participated in Sudarshan Kriya Yoga, Al Ameen Journal of Medical Sciences,3(1):42-49.

Pullen, P.R., Nagamia, S.H., Mehta ,P.K., Thompson, W.R., Benardot, D., Hammoud, R., Parrott, J.M., Sola S, Khan BV. (2008). Effects of yoga on inflammation and exercise capacity in patients with chronic heart failure. J Card Fail 14:407-413.

https://doi.org/10.1016/j.cardfail.2007.12.007

Sarvottam , K. \& Yadav , R.( 2014) . Obesity -related inflammation \& cardiovascular disease:efficacy of a yoga based lifestyle intervation. Indian J Med Res 139(6),822-834.

Vempati, R.P., Telles, S.(2002), Yoga-based guided relaxation reduces sympathetic activity judged from baseline levels. Psychol Rep 90:487-494.

https://doi.org/10.2466/pr0.2002.90.2.487

Sharma , S.R.(1979). Pragya yoga for happy and healthy life. Shantikunja Haridwar: shrivedmata gayatri trust santikunj (haridwar),Uttarakhan.

Gadham , J. , Srikanth ,S. , and Rooha V.(2015).Effect of yoga on obesity, hypertension and lipid profile .International journal of Research in medical science.3(5):1061-1065

https://doi.org/10.5455/2320-6012.ijrms20150506

Khare , K.C. and Kauthker , G. (2002).Lean body mass and lipid profile in healthy persons practicing yoga.Yoga-Mimansha.36(2).123-128

Madape , A. , Bharsankar , J. ,and Phatak , M .(2015).Effect of Raja-yoga meditation on the lipid profile of Healthy adult in central India. Journal of medical science and health . 1(1).10-30
Seo , D., Lee ,S. R.,(2012).Yoga Training improves metabolic parameters in Obese Boys. The Korean Journal of physiology and pharmacology . 16 (3):175180

https://doi.org/10.4196/kjpp.2012.16.3.175

Mody , B. S. (2011).Acute effect of surya- namskar on the cardiovascular and metabolic system .Jouranal of Body movement and Acutetherapies.15(1).34 https://doi.org/10.1016/j.jbmt.2010.05.001

Nilakathan , S. , Metri , K. , Raghuram ,N. , and Hongasandra , N.(2016). Effect of 6 months yoga practice on Lipid profile, thyroxine medication and serum TSH level in women suffering from hypothyroidism - A Pilot Study . Journal of complementary and integrative medicine.13(2):79 https://doi.org/10.1515/jcim-2014-0079

Prasad, K.V.V., Madhavi, S., Sitaramraju, P. Venkata reddy, M., Sahay, B.K. and Murthy, K.J.R.(2006).Impact of pranayam and yogasana on lipid profile in normal healthy volunteers. Journal of exercise physiology.9(1).

Jain, S.C. and Talukdar , B.1995. Role of yoga in control of hyperglycemia in middle aged patients of non insulin dependent diabetes mellitus. Indian $\mathrm{J}$ Clin.Biochem.10(2),62-65.

https://doi.org/10.1007/BF02871003

Singh, S., Malhotra, V., Singh, K.P., Sharma, S.B. , Madhu, S.V. , Tandon, O.P.(2001) . A preliminary report on the role of yoga asanas on oxidative stress in non-insulin dependent diabetes mellitus .International Journal of Clinical Biochemastry;16:216220

https://doi.org/10.1007/BF02864866

Mahapuri HH, Shete S U, Bera TK, Effect of yogic exercise on superoxide dismutase levels in diabetics(2008). International Journal of Yoga; 1:2126.

https://doi.org/10.4103/0973-6131.36792

Tells, S., Sharma, S. Yadav, A. Singh, N., \& Acharya B. (2014).A comparative controlled trial comparing the effect of yoga and walking for overweight and obese adults. Medical Science Monitor, 20, 894-904 https://doi.org/10.12659/MSM.889805

Dhananjai, S., Sadashiv, Tiwari, S., Dutt, K., \& Kumar, R.(2013). Reducing psychological distress and obesity through Yoga practice. International Journal of Yoga, 6(1), 66-70 https://doi.org/10.4103/0973-6131.105949 